\title{
A Comparative Study on the Influence of Nano and Micro Particles on the Workability and Mechanical Properties of Mortar Supplemented with Fly Ash
}

\author{
Mostafa Seifan *D, Shaira Mendoza and Aydin Berenjian \\ School of Engineering, Faculty of Science and Engineering, The University of Waikato, \\ Hamilton 3216, New Zealand; mshaifrances@gmail.com (S.M.); aydin.berenjian@waikato.ac.nz (A.B.) \\ * Correspondence: mostafa.seifan@waikato.ac.nz
}

check for updates

Citation: Seifan, M.; Mendoza, S.; Berenjian, A. A Comparative Study on the Influence of Nano and Micro Particles on the Workability and Mechanical Properties of Mortar Supplemented with Fly Ash. Buildings 2021, 11, 60. https:// doi.org/10.3390/buildings11020060

Academic Editors: Lech Czarnecki, Oliver Kinnane and Richard O' Hegarty

Received: 15 December 2020

Accepted: 5 February 2021

Published: 10 February 2021

Publisher's Note: MDPI stays neutral with regard to jurisdictional claims in published maps and institutional affiliations.

Copyright: (c) 2021 by the authors. Licensee MDPI, Basel, Switzerland. This article is an open access article distributed under the terms and conditions of the Creative Commons Attribution (CC BY) license (https:/ / creativecommons.org/licenses/by/ $4.0 /)$.

\begin{abstract}
In this study, the effects of micro- $\mathrm{Al}_{2} \mathrm{O}_{3}$ (MA) and nano- $\mathrm{Al}_{2} \mathrm{O}_{3}$ (NA) on the mechanical properties and durability performance of a mortar containing fly ash (FA) were investigated. In the first step, MA and NA were added to the mortar (as a cement replacement) at dosages of $0 \%$, $5 \%, 10 \%$ and $15 \%$ by weight. The flowability of the mixture containing NA and MA showed a dosage-dependent behavior, and the addition of MA resulted in a higher flow spread compared with NA. The flow spread increased at $5 \%$ (for both NA and MA), and a further increase in the particle content to $10 \%$ and $15 \%$ decreased the flow spread value. Although the presence of MA and NA contributed to increasing the compressive strength as the particle content increased, the addition of NA resulted in a greater increase in compressive strength (40\% increase when adding $15 \%$ of NA). The highest splitting tensile strength was obtained when $10 \%$ NA was used, and a further increase in the particle content decreased the splitting tensile strength. In the optimization step, the effect of a binder replacement with FA $(10,20$ and 30\%) in the presence of $10 \%$ NA as the optimum level of additive was investigated. Generally, the addition of FA decreased the compressive strength. The highest drop in compressive strength was noticed at early ages, and there was no significant difference in strength development from 14 days to 28 days. A decreasing trend in the splitting tensile strength was observed with the addition of FA content.
\end{abstract}

Keywords: mortar; fly ash; micro $\mathrm{Al}_{2} \mathrm{O}_{3}$; nano $\mathrm{Al}_{2} \mathrm{O}_{3}$; nanomaterial; mechanical properties

\section{Introduction}

Concrete is one of the most-used materials in the world, due to its high compressive strength, availability and low price. However, it has some weaknesses, such as a low tensile strength and being susceptible to cracking under excreted stresses. Apart from these, the strength of concrete highly depends on the degree of cement hydration. So far, different types of nano and microscale additives have been developed to further increase the performance of concrete. These types of additives can act as filler or modify the physical and chemical processes.

During recent years, nanotechnology has advanced the functionality and performance of many materials so they may be used more effectively in a wide range of disciplines, such as construction and building materials. Although the meaning of nanotechnology varies from discipline to discipline, it is commonly defined as understanding, controlling and restructuring matter with a size less than $100 \mathrm{~nm}$ for producing materials with fundamentally new characteristics [1]. Nanomaterials have high chemical reactivities due to a high surface-area-to-volume ratio [2]. In construction materials, particularly cementitious materials, nanoscience and nanoengineering have significantly helped to understand nanoscale properties (chemical and physical). These characteristics are critical, as they affect the performance of cementitious materials at the macroscopic level. With the aid of nanoscience, a better understanding of how the structure of cementitious materials 
affects macroscale properties is achieved, while nanoengineering offers the techniques to manipulate the structure at the nanometer scale to produce a multifunctional cementitious material with superior mechanical properties and durability performance. To control the behavior and add more properties, concrete can be nanoengineered by the addition of nanoscale materials. For example, in cementitious composites, nanomaterials act as nucleation centers, contributing to the development of the hydration of Portland cement (PC) and increasing the amount of calcium silicate hydrate $(\mathrm{C}-\mathrm{S}-\mathrm{H})$ gel in the paste through a pozzolanic reaction [3].

It was reported that the addition of certain nanoparticles allowed the cement-based materials to exhibit unique features, such as self-sensing and self-cleaning [4,5]. Among all the tested nano-sized particles were nanocarbons, nano- $\mathrm{SiO}_{2}$, nano- $\mathrm{Fe}_{2} \mathrm{O}_{3}$, nano- $\mathrm{Al}_{2} \mathrm{O}_{3}$ and nano- $-\mathrm{TiO}_{2}$. Nanocarbons, particularly carbon nanotubes and carbon nanofibers, have received much attention for improving the characteristics of concrete, as nanocarbons possess unique features such as excellent thermal properties and a high tensile strength and Young's modulus. However, the poor dispersion of nanocarbons in cement-based materials due to their high hydrophobicity is the limitation of using such enhancers in cementitious composites [1]. Therefore, researchers have attempted to evaluate the performance of modified concrete with other potential nanoparticles. For instance, Qing et al. [6] investigated the effect of nano- $\mathrm{SiO}_{2}$ additions on the properties of fresh and hardened cement paste to assess whether this inclusion can improve the characteristics of cement-based composites compared with silica fume. The results showed that the addition of nano- $\mathrm{SiO}_{2}$ made the cement paste thicker and also accelerated the cement hydration process. Compared with silica fume, the presence of nano-sized silica particles increased the compressive strength and bond strength of the paste-aggregate interface. The same observations were also noticed by Jo et al. [7] when they included nano- $\mathrm{SiO}_{2}$ in cement mortar. Iron oxide is another type of nanoparticle that has been used to modify the properties of concrete. In 2012, Khoshakhlagh et al. [8] evaluated the performance of modified, self-compacting concrete with nano- $-\mathrm{Fe}_{2} \mathrm{O}_{3}$. It was found that the addition of nano- $-\mathrm{Fe}_{2} \mathrm{O}_{3}$ up to $4 \mathrm{wt} . \%$ increased the compressive strength and decreased the water permeability. Likewise, Sikora et al. [5] studied the influence of nano- $\mathrm{Fe}_{2} \mathrm{O}_{3}(1-5 \mathrm{wt} . \%)$ on the microstructure and mechanical properties of cementitious composites. It was found that nano- $\mathrm{Fe}_{2} \mathrm{O}_{3}$ acted as a filler in the concrete matrix, which ultimately resulted in an increase in the durability of the concrete by decreasing the porosity, while it did not have any effect on cement hydration. This was mainly due to the characteristics of the nano- $\mathrm{Fe}_{2} \mathrm{O}_{3}$ particles which did not have pozzolanic activity. The authors also observed an up to $20 \%$ increase in the compressive strength of the concrete when nano- $\mathrm{Fe}_{2} \mathrm{O}_{3}$ was supplemented in the composite. In another investigation, the effect of nano- $\mathrm{Fe}_{2} \mathrm{O}_{3}$ on the piezoresistive behavior and compressive strength of cement paste for oil well applications was evaluated [9]. The experimental results indicated that cement paste modified with nano- $\mathrm{Fe}_{2} \mathrm{O}_{3}$ had better sensing properties (750 times higher than unmodified) that facilitated monitoring at various stages of construction, and even during the service life of the wells. In terms of hardened properties, the modified cement paste with nano- $\mathrm{Fe}_{2} \mathrm{O}_{3}$ exhibited a higher compressive strength than the reference specimen $(40 \%$ at 28 days), while for the setting time, the behaviour was not affected by the addition of nano- $\mathrm{Fe}_{2} \mathrm{O}_{3}$ fillers. Moreover, the addition of nano- $\mathrm{Fe}_{2} \mathrm{O}_{3}(1 \mathrm{wt} . \%)$ increased the modulus of elasticity by $28 \%$ for 28 days in the cured sample. In another study, Oltutu and Sahin investigated the single and synergistic effects of nano- $\mathrm{SiO}_{2}$, nano- $\mathrm{Al}_{2} \mathrm{O}_{3}$ and nano- $\mathrm{Fe}_{2} \mathrm{O}_{3}$ on the mechanical properties of cement mortar containing silica fume [10]. Although the inclusion of single nanoparticles increased the compressive strength of the silica fume-modified mortar, the binary and ternary interactions of nanoparticles led to decreasing the physical and mechanical characteristics of the cement mortar specimens. Therefore, as can be seen from the literature, the presence of nanoparticles can have a positive or negative effect on the fresh and hardened properties of concrete, depending on the type, size and content of particles. 
Although concrete has unique mechanical properties and is widely available at an affordable price, it is not an environmentally friendly material. The manufacturing of PC is an energy-intensive process that releases a massive amount of greenhouse gases. The cement industry alone is responsible for $7 \%$ of $\mathrm{CO}_{2}$ emissions, where the mixture of $\mathrm{CaCO}_{3}$ and clay is sintered at $1500{ }^{\circ} \mathrm{C}$ [11]. Therefore, the utilization of pozzolans as a partial replacement for PC has attracted the attention of researchers. Due to the environmental impact of cement production, the addition of supplementary cementitious materials such as fly ash (FA), silica fume, blast furnace slag and metakaolin to PC has drawn interest. Fly ash is the most widely used industrial waste product generated from burning, pulverized coal in electric generation power plants. It has a pozzolanic property and micro-filler effect, which can improve the resistance of concrete against the ingress of harmful ions [12].

Due to the environmental concerns associated with the production of cement, the replacement of cement with byproduct materials such as FA could be an alternative solution. However, it is known that the early strength of fly ash-based concrete is significantly lower than cement-based concrete, and this may hinder its usage for those applications where early strength is needed. Thus, the inclusion of pozzolans to enhance the cement hydration over early ages can be a solution to address the limitations of fly ash-based concrete. The synthesis and addition of nano and microscale materials into a concrete matrix offers the possibility for the production of new cement additives. Therefore, in this study, the effects of micro- $\mathrm{Al}_{2} \mathrm{O}_{3}$ (MA) and nano- $\mathrm{Al}_{2} \mathrm{O}_{3}$ (NA) on the properties of fresh and hardened mortar were screened. Thereafter, an optimization study was performed to investigate the effects of binder replacement with fly ash on the mechanical properties of mortar in the presence of the optimum percentage of NA.

\section{Materials and Methods}

\subsection{Materials and Mixture Proportions}

The materials used in this study were cement (PC with a specific surface area and density of $330 \mathrm{~m}^{2} / \mathrm{kg}$ and $3.05 \mathrm{~g} / \mathrm{cm}^{3}$ in accordance with the New Zealand standard NZS1322: 2009), river sand, NA with particle sizes less than $15 \mathrm{~nm}$, MA with particle sizes ranging between 2 and $10 \mu \mathrm{m}$, and low-calcium FA purchased from a local source from a pulverized coal combustion power plant in Australia. The fly ash used in this study was class F fly ash, driven from coal-fired (bituminous) boilers at a temperature of $1700{ }^{\circ} \mathrm{C}$. The particulates were collected from dust-collecting systems, and the $\mathrm{CaO}$ content was less than $7 \%$. Nano- and micro-sized alumina particles can be produced through different processes, such as grinding alumina powder to the micrometer and nanometer level using specific mills or the decomposition of chemically synthesized $\mathrm{AlOOH}$ or $\mathrm{Al}(\mathrm{OH})_{3}$ to micro or nano alumina at a controlled temperature and pressure for a specific time. Although the production of these particles ended up liberating $\mathrm{CO}_{2}$, the percentage of added particles was considerably small and, therefore, the $\mathrm{CO}_{2}$ footprint was significantly lower than cement production.

The proportions of the 10 mixtures prepared for this study are presented in Table 1 , which was adopted from the previous study [13]. A water:binder:sand ratio of 0.5:1:2.5 was used consistently in all fresh mortar mixtures. At the screening stage, binder was replaced by $5 \%, 10 \%$ and $15 \%$ NA and MA. Further study was conducted with the mixture containing the optimum dosage of $\mathrm{Al}_{2} \mathrm{O}_{3}$ particles, where binder was replaced by $10 \%$, $20 \%$ and $30 \%$ FA. To prepare the fresh mortars, each component was weighed according to the correct mixture proportions. The dry components were hand-mixed for $1 \mathrm{~min}$, then mechanically mixed with water for $4 \mathrm{~min}$ to achieve a homogeneous mixture. The mixtures were transferred and compacted into cylindrical molds, using a tamping rod as per ASTM C311-16 [14]. The samples were dried on a flat surface at room temperature and removed from the molds after $24 \mathrm{~h}$. Afterward, curing was conducted in variations to suit the tests on the compressive strength, splitting tensile strength and capillary water uptake. 
Table 1. Proportions of mixtures with different micro- $\mathrm{Al}_{2} \mathrm{O}_{3}$, nano- $\mathrm{Al}_{2} \mathrm{O}_{3}$ and fly ash contents.

\begin{tabular}{cccccc}
\hline Sample ID & Micro $\mathbf{A l}_{\mathbf{2}} \mathbf{O}_{\mathbf{3}} \mathbf{( \% )}$ & Nano $\mathbf{A l}_{\mathbf{2}} \mathbf{O}_{\mathbf{3}} \mathbf{( \% )}$ & Fly Ash (\%) & Water-to-Binder Ratio & Sand-to-Binder Ratio \\
\hline Ref. & 0 & 0 & 0 & 0.5 & 0.5 \\
MA5-100 & 5 & 0 & 0 & 0.5 & 2.5 \\
MA10-100 & 10 & 0 & 0 & 0.5 & 2.5 \\
MA15-100 & 15 & 0 & 0 & 0.5 & 2.5 \\
NA5-100 & 0 & 5 & 0 & 0.5 & 2.5 \\
NA10-100 & 0 & 10 & 0 & 0.5 & 2.5 \\
NA15-100 & 0 & 15 & 0 & 0.5 & 2.5 \\
NA10-90 & 0 & 5 & 10 & 0.5 & \\
NA10-80 & 0 & 5 & 20 & 0.5 & \\
NA10-70 & 0 & 5 & 30 & & 2.5 \\
\hline
\end{tabular}

\subsection{Test Methods}

\subsubsection{Evaluation of Fresh Properties}

The workability of fresh mortars was tested immediately after being prepared by performing a standard flow table test, in accordance with ASTM 1437-16 [15]. Fresh mortar was transferred into a mold by layer, where the first layer was approximately $25 \mathrm{~mm}$ and the second layer was filled up to the brim. Both layers were compacted using a tamper. The mold was then removed, and the flow table was dropped 25 times from the same height. The diameter of the flow spread was measured, and the test results were recorded as the average of four measurements.

\subsubsection{Mechanical Properties}

Compressive strength tests were performed in agreement with ASTM C109-16 [16] using a concrete compression machine (VJT6000, VJ Tech, Reading, UK) to subject cylindrical samples to compressive stress. The compressive strengths of the samples were tested at 7 , 14 and 28 days of curing. The resulting values for compressive strength were taken as the average of tested specimens.

Meanwhile, splitting tensile tests were carried out in compliance with ASTM C49616 [17] using a tensile tester machine (Instron 4204, Frank Bacon Machinery Sales Co., Warren, $\mathrm{OH}, \mathrm{USA}$ ). Longitudinal stress was applied to the cylindrical samples at a rate of $1 \mathrm{~mm} / \mathrm{min}$. Splitting tensile strength tests were conducted for samples cured at 7, 14 and 28 days, and the results were taken as the average of the specimens tested. For testing both the compressive and splitting tensile strengths, the samples with diameters of $50 \mathrm{~mm}$ and heights of $100 \mathrm{~mm}$ were prepared, and the average result of the three specimens was reported as the mean value.

\subsubsection{Water Absorption}

Capillary water absorption tests were conducted in compliance with ASTM C140315 [18] to evaluate the durability of the samples. The sample preparation method was similar to the compressive and splitting strength test samples and differed only in the curing method. The water absorption specimens were placed vertically inside a watertight bag for 28 days. At the day 28, the samples were taken out of the bags and placed inside an oven set at a temperature of $100{ }^{\circ} \mathrm{C}$ for $24 \mathrm{~h}$. After the samples were allowed to cool down to ambient temperature, the initial weight was recorded to the nearest $0.01 \mathrm{~g}$, and the samples were immersed in a special test container. The samples were immersed in approximately $3 \mathrm{~mm}$ of water in a supported container. The water uptake was observed by measuring the sample weight at intervals of $15 \mathrm{~min}, 30 \mathrm{~min}, 1 \mathrm{~h}, 2 \mathrm{~h}, 3 \mathrm{~h}, 4 \mathrm{~h}, 6 \mathrm{~h}, 24 \mathrm{~h}$, 2 days, 3 days and up to 6 days. The water absorption values were determined using Equation (1), and the result was recorded as the average of the tested specimens:

$$
A_{T}=\frac{\left(W_{T}-W_{0}\right) \times 10000}{A}
$$


where $A_{T}, W_{T}, W_{0}$ and $A$ are water uptake, specimen weight at a given time (T), initial weight of the sample and cross-sectional area, respectively.

\subsubsection{Characterization of Materials}

The particle size distribution was determined using a Malvern Mastersizer instrument (3000, Malvern Panalytical, Malvern, UK). Powders of MA, FA, cement and sand were dispersed in isopropanol and placed in a dispenser feeding into the Mastercizer instrument. The working range was between obscuration values of $10 \%$ and $30 \%$, with measurements taken at a mixing speed of $2700 \mathrm{rpm}$ for $20 \mathrm{~s}$. The results for the particle size were recorded in $\mu \mathrm{m}$, and the results for the volume densities were reported as percentages.

Meanwhile, the structural information of the samples was analyzed by Fourier transform infrared spectroscopy (FTIR, Bruker, MA, USA). NA and MA in powder form were diluted with $\mathrm{KBr}$, with the $\mathrm{KBr}$ ratio being $1 \%$. Then, using a PerkinElmer spectrum, the test was conducted at ambient temperature, and the data was collected within a range of wavenumbers (from 4000 to $400 \mathrm{~cm}^{-1}$ ). Furthermore, characterization of the materials was conducted, and the size and morphology of the samples were evaluated using scanning electron microscopy (SEM) (Hitachi S-4700, Hitachi High-Tech Science Corporation, Tokyo, Japan). Powders of NA and MA, FA and cement were placed on sticky carbon tape and transferred onto a sputter coater (Hitachi E1030, Hitachi High-Tech Science Corporation, Tokyo, Japan) to be coated with platinum. The samples were then loaded into a highvacuum chamber, and analysis was performed with a voltage of $15 \mathrm{kV}$. In addition, X-ray diffraction (XRD) analysis was performed to characterize $\mathrm{FA}$ and $\mathrm{Al}_{2} \mathrm{O}_{3}$ particles. Briefly, the powder was packed into a steel sample holder and compacted to achieve a flat surface. The sample was then mounted on a sample holder and tested using a Panalytical empyrean reflectometer $\left(\mathrm{CuK} \alpha\right.$; Panalytical, Malvern, UK). The testing range was set to $10-80^{\circ}$ with a step size of $0.0530^{\circ}$ and a working voltage and current of $45 \mathrm{kV}$ and $40 \mathrm{~mA}$, respectively.

\section{Experimental Results}

\subsection{Characterization of Micro and Nanoparticles, Cement and Fly Ash}

The size and morphology of MA and NA are compared in Figure 1a,b. The results showed that MA had an amorphous structure with sizes ranging between 2-10 $\mu \mathrm{m}$, while the micrograph of NA revealed a cluster of rounded particles with individual particle sizes less than $15 \mathrm{~nm}$. Meanwhile, the characterization of fly ash and cement began with a comparison of the size and morphology. As shown in Figure 1c,d, it can be observed that the FA particles were in ball shapes, whereas cement had an amorphous and bulky structure. The size of the MA observed via SEM was further confirmed with the Mastercizer results in Figure 2, where MA showed a broad peak between 0.1 and $10 \mu \mathrm{m}$.

Furthermore, structural information in the form of the FTIR spectra of both MA and NA are shown in Figure 3. The peaks of MA and NA were alike; however, NA exhibited a higher intensity, which was due to the types of bonds found in $\mathrm{Al}_{2} \mathrm{O}_{3}$ being present at a higher amount in nanoscale. This may be due to the presence of surfactants brought about during the synthesis processes. The $\mathrm{O}-\mathrm{H}$ vibrations of $\mathrm{Al}_{2} \mathrm{O}_{3}$ particles are shown as the peaks around $3468 / 3439 \mathrm{~cm}^{-1}[19,20]$, while the $\mathrm{C}-\mathrm{H}$ bonds are interpreted as the peaks observed at $2917 / 2918 \mathrm{~cm}^{-1}$. Moreover, peaks within the range of $1630 / 1639 \mathrm{~cm}^{-1}$ and $1384 / 1385 \mathrm{~cm}^{-1}$ both correspond to the stretching of carboxyl groups $(\mathrm{C}=\mathrm{O})$ [20]. Finally, the high peak observed at $640 / 638 \mathrm{~cm}^{-1}$ conformed to the stretching vibrations of Al-O found in alumina [20]. Moreover, the characterization results of MA and NA by XRD are shown in Figure 4. The XRD patterns for both $\mathrm{Al}_{2} \mathrm{O}_{3}$ particles were similar and agreed with the previous study [21]. Notable peaks were at angles of $(2 \theta) 35^{\circ}, 40^{\circ}-45^{\circ}$ and $55^{\circ}-60^{\circ}$, which confirmed the $\alpha-\mathrm{Al}_{2} \mathrm{O}_{3}$ phase of aluminum oxide. The intensity of the peaks was higher with NA compared with MA, which was due to the presence of nanocrystallites generated by the crushing of particles during deposition [21]. Figure 5 shows the XRD characteristic spectra of FA. As can be seen from the XRD pattern, the two major crystalline 
phases detected in the FA were mullite and quartz. The most intensive peak appeared at an angle between $25^{\circ}$ and $35^{\circ}$. This characteristic is attributed to the amorphous phase.
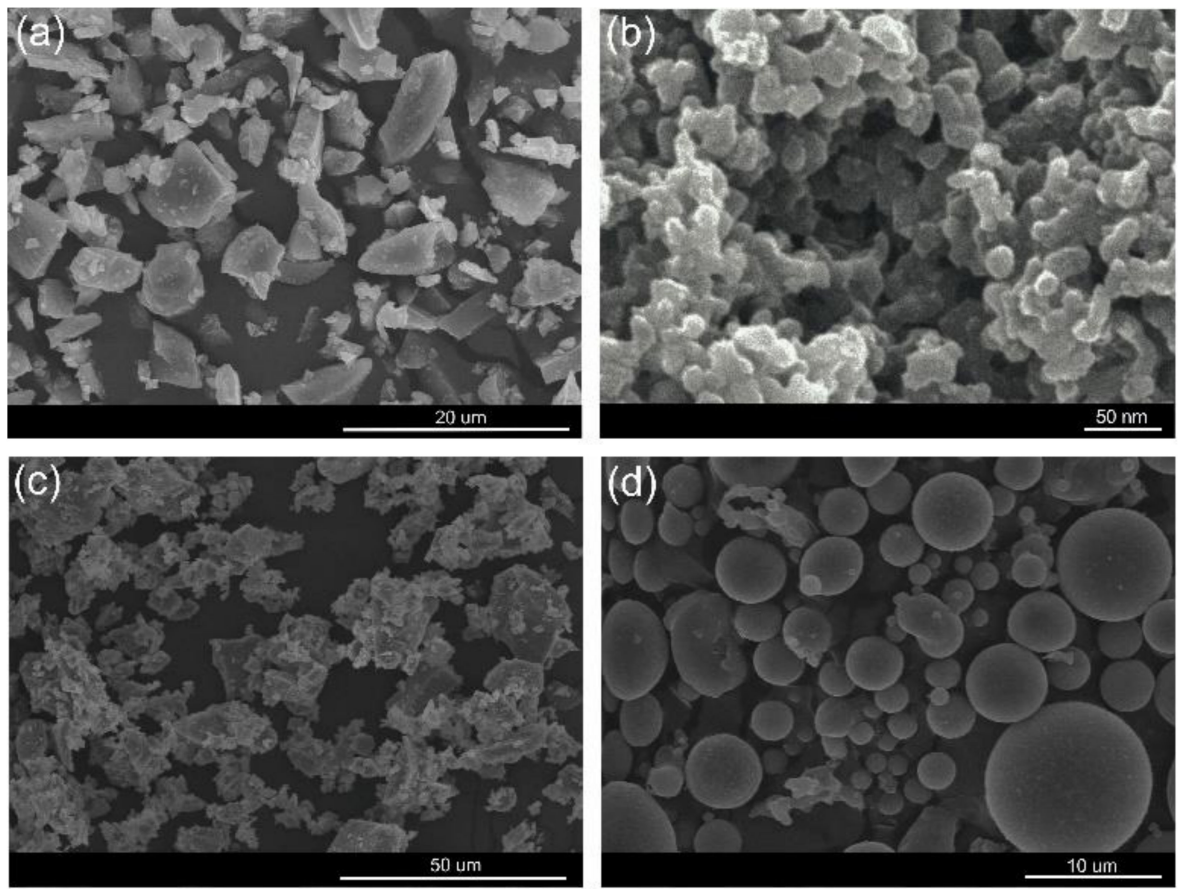

Figure 1. Scanning electron microscopy (SEM) micrographs of (a) micro- $\mathrm{Al}_{2} \mathrm{O}_{3}$ (b) nano- $\mathrm{Al}_{2} \mathrm{O}_{3}$, (c) cement particles and (d) fly ash.

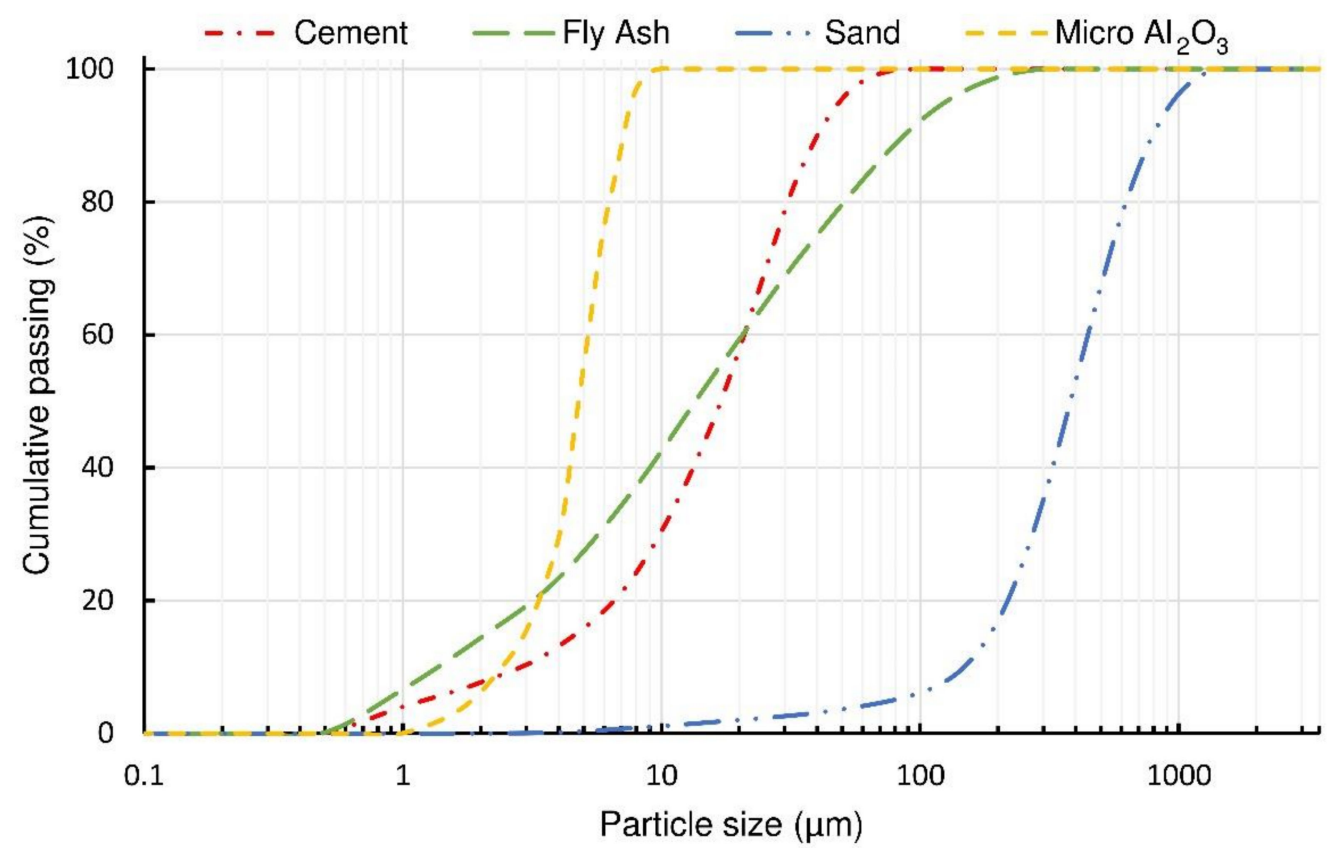

Figure 2. Cumulative particle size distribution for cement, fly ash, fine aggregate and micro- $\mathrm{Al}_{2} \mathrm{O}_{3}$. 



Figure 3. Fourier transform infrared spectroscopy (FTIR) spectra of (a) micro- $\mathrm{Al}_{2} \mathrm{O}_{3}$ and (b) nano$\mathrm{Al}_{2} \mathrm{O}_{3}$.

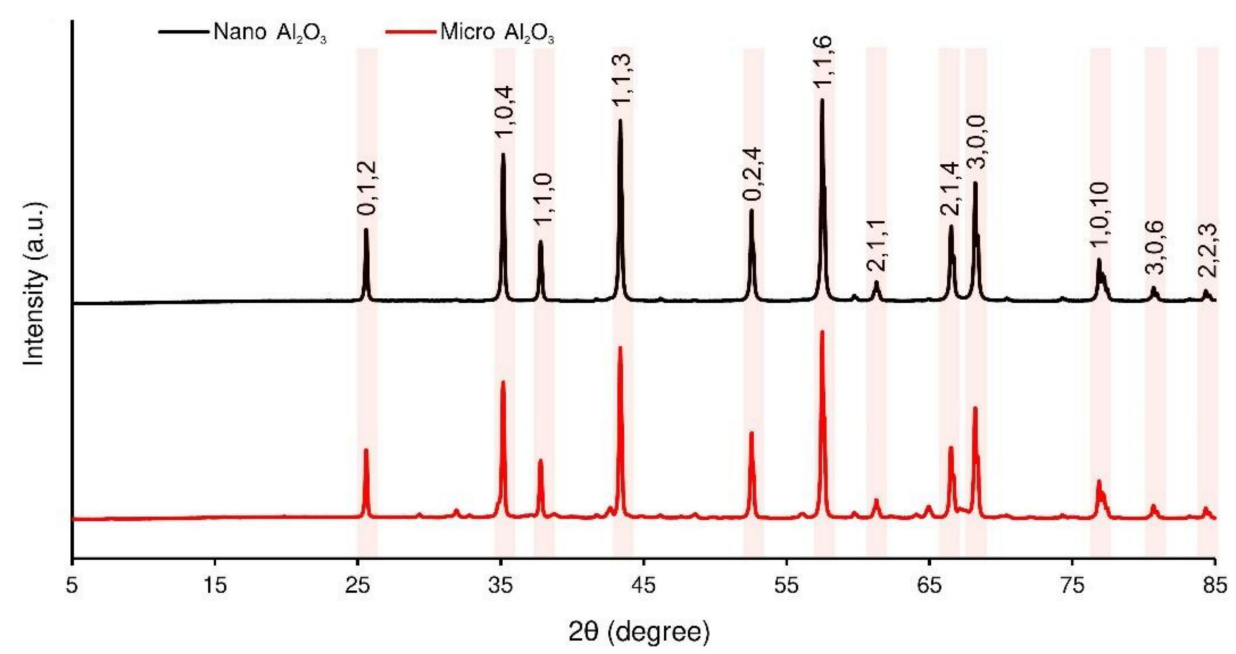

Figure 4. $X$-ray diffraction (XRD) spectra of micro- $\mathrm{Al}_{2} \mathrm{O}_{3}$ and nano- $\mathrm{Al}_{2} \mathrm{O}_{3}$. 




Figure 5. XRD spectra of fly ash (FA) powder.

\subsection{Effect of Particles on the Fresh and Mechanical Properties of Mortar}

The workability of the fresh mortar mixtures was determined by a standard flow table test, and the results in Figure 6a show that the dosage of NA and MA had a slight effect on the fresh properties. With an initial dosage of $5 \%$ NA and MA, the flow spread appeared to increase by $5.5 \%$ and $7.4 \%$, respectively, compared with the reference. Furthermore, an increasing amount of the particles tended to decrease the flowability; however, the workability was still acceptable. Up to a $15 \%$ addition of NA and MA caused the flow spread to decrease by $8.8 \%$ and $8.2 \%$, respectively, compared with the reference, and $13.6 \%$ and $14.5 \%$, respectively, compared with the initial mixture containing 5\% NA and MA. Moreover, it can be observed that, in all dosages of $\mathrm{Al}_{2} \mathrm{O}_{3}$ particles, the workability of the samples with NA was slightly lower than the workability of the samples with MA. For example, at $5 \% \mathrm{NA}$, the flow spread was $3.5 \mathrm{~mm}$ less than the flow spread at $5 \% \mathrm{MA}$.

The effects of the particle dosage on the strength of the specimens are shown through the compressive and splitting tensile test results in Figure 6b,c. A general trend of an increasing compressive strength with an increasing particle content (both NA and MA) was observed. Initially, with the presence of $5 \% \mathrm{NA}$ and MA, the compressive strength increased by $34 \%$ and $9.9 \%$, respectively, compared with the reference. A further addition of up to $15 \%$ NA and MA further increased the compressive strength by $42 \%$ and $22.7 \%$, respectively, compared with the reference. Although incorporating both NA and MA had positive effects on the compressive strength, the strength gain with NA was still higher than the strength gain with MA. For example, with the addition of $15 \% \mathrm{NA}$, the highest compressive strength of $14.6 \mathrm{MPa}$ among the samples was achieved, which was $15.7 \%$ higher than the strength achieved using the same dosage of MA.

The results from the splitting tensile strength tests are summarized in Figure 6c. The pattern revealed that the optimum splitting tensile strength at $1.8 \mathrm{MPa}$ was obtained with the addition of $10 \% \mathrm{NA}$, increasing the splitting tensile strength by $8.2 \%$ compared with the reference. Again, it was observed that the addition of NA was more effective at increasing the compressive strength than the addition of MA, which was observed in all particle additions from $5 \%$ to $15 \%$. For instance, at a $10 \%$ particle dosage, the strength of the specimen with NA was 5.2\% higher than the strength of the specimen with MA, even though the dosage was similar. Moreover, increasing the particle content up to $15 \%$ only tended to decrease the splitting tensile strength. It was seen that the splitting tensile strength at $15 \%$ NA and MA decreased by $2.4 \%$ and $8.3 \%$, respectively, when compared with the reference, noting that the strength reduction with the MA addition was larger than the strength reduction with the NA addition. Therefore, the optimum mixture for further study was determined to be at $10 \% \mathrm{NA}$, since it showed a reasonable increase in compressive strength and had the highest splitting tensile strength. Figure 7 illustrates the images of the tested samples after splitting tensile and compression testing. 

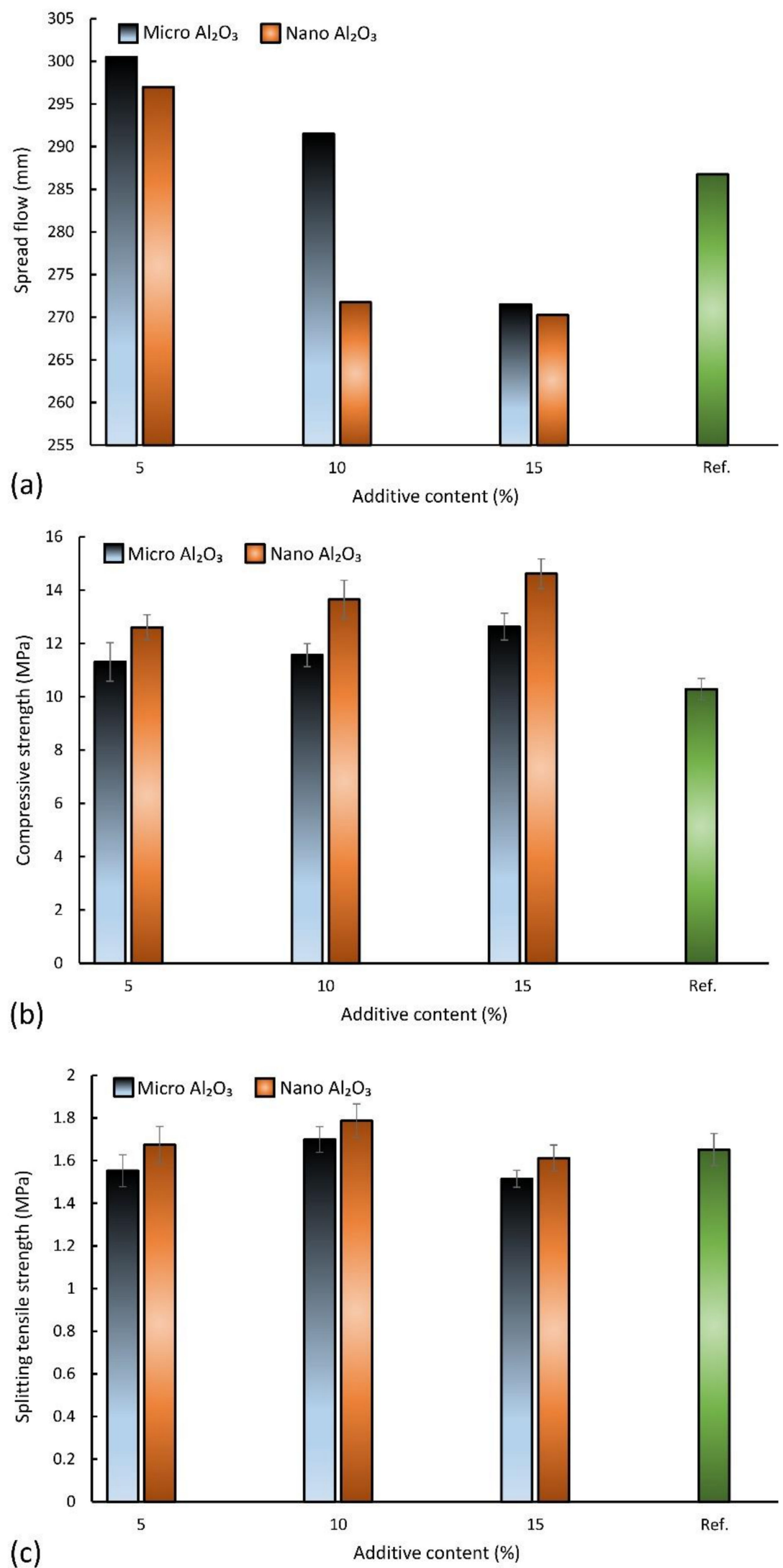

Figure 6. (a) Spread flow, (b) compressive strength and (c) splitting tensile strengths of mortar in the presence of micro- and nano- $\mathrm{Al}_{2} \mathrm{O}_{3}$ particles. 

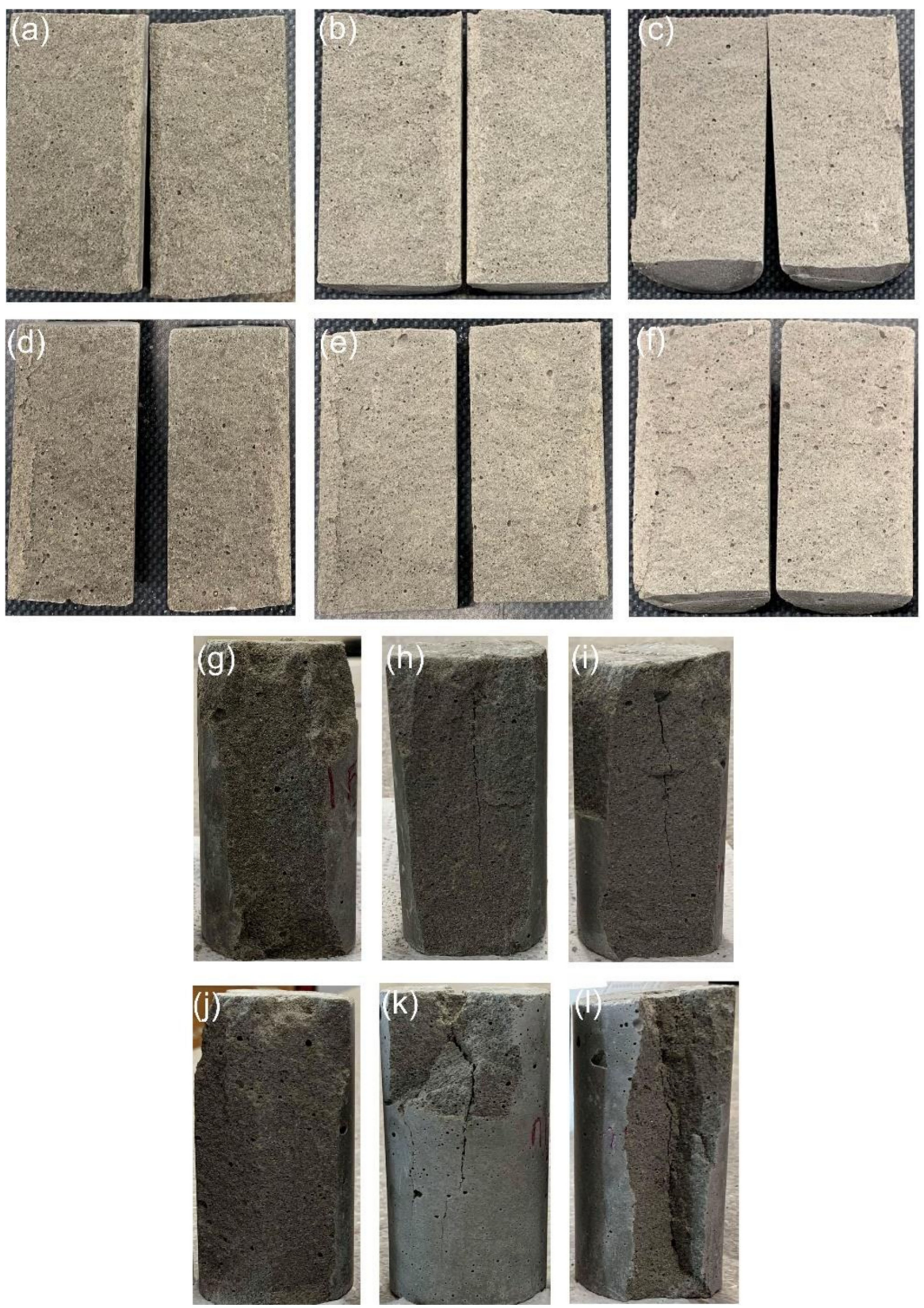

Figure 7. Sample images of the tested specimens' (a-c) splitting tensile strengths (5-15\% micro- $\mathrm{Al}_{2} \mathrm{O}_{3}$ (MA)), (d-f) splitting tensile strengths (5-15\% nano- $\mathrm{Al}_{2} \mathrm{O}_{3}$ (NA)), (g-i) compressive strengths (5-15\% MA) and (j-1) compressive strengths (5-15\% NA).

\subsection{Effect of the Optimum Dosage of $\mathrm{Nano}_{-} \mathrm{Al}_{2} \mathrm{O}_{3}$ on the Fresh Properties and Strength Development}

Based on the results of the screening study, it was determined that the optimum mixture was with the addition of 10\% NA. The strength development of NA10-100 was then examined at varying aging durations of 7, 14 and 28 days. The results in Figure 8 a show the development of the compressive strength over time, which revealed that the strength gain of the sample with $10 \%$ NA was smaller in its curing duration when compared with the strength development of the reference. At 7 days, it can be observed that the compressive strength of NA10-100 was 32.7\% higher than that of the reference. The compressive strength of the reference caught up with that of NA10-100 at 14 days, where there was only a $0.1 \mathrm{MPa}$ difference. Finally, at 28 days, the compressive strength of the reference surpassed that of NA10-100 with a $2.57 \mathrm{MPa}$ difference. Overall, the strength gain of 
the optimum sample was $19 \%$, whereas the strength gain of the reference was $71 \%$ over 28 days. Regardless, the specimen with $10 \%$ NA still gained significant strength over 28 days, where the compressive strength of $16.3 \mathrm{MPa}$ was achieved.
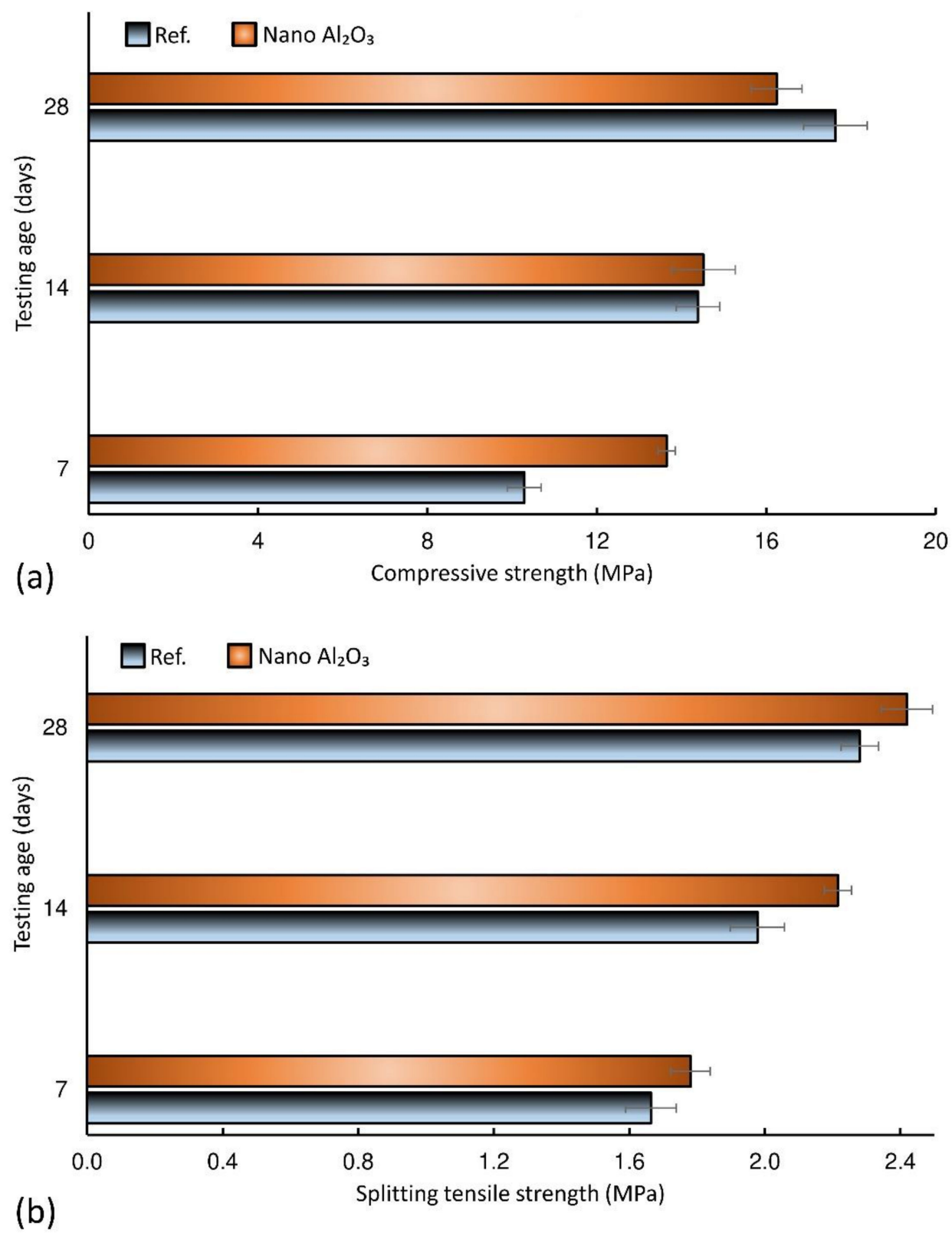

Figure 8. (a) Compressive strength and (b) splitting tensile strength development in the presence of the optimum concentration of nano- $\mathrm{Al}_{2} \mathrm{O}_{3}$ particles $(10 \%)$.

In comparison, the splitting tensile strength results, presented in Figure $8 b$, show that the splitting strength of specimens with $10 \%$ NA was higher than that of the reference, regardless of the curing duration. Overall, NA10-100 gained 35.8\% splitting strength, while the reference gained $37 \%$ splitting strength between 7 and 28 days. Furthermore, the optimum sample NA5-100 reached the highest splitting tensile strength of $2.42 \mathrm{MPa}$ at 28 days. Although the splitting tensile strength of the specimens with $10 \%$ NA was generally higher than that of the reference, it can also be noticed that the difference in splitting strengths was increased as the curing time increased. For example, at 7 days, the strength of NA10-100 was $0.12 \mathrm{MPa}$ more than that of the reference, and at 14 days, the strength of the optimum sample was 0.24 MPa higher than that of the reference. 


\subsection{Effect of the Binder Replacement with Fly Ash in the Presence of $\mathrm{Nano}^{-\mathrm{Al}_{2} \mathrm{O}_{3}}$}

The flow table test results presented in Figure 9 reveal that the FA content in the optimum mixture affected the workability slightly. At a 10\% FA addition into the optimum sample, the flow spread initially decreased by $29.5 \%$ compared with the reference. However, when increasing the FA addition up to $30 \%$, the change in flow spread decreased to only $8.3 \%$ when compared with the reference. Between $10 \%$ and $30 \%$ fly ash, the discrepancy in the collapse diameter was small at $39.7 \mathrm{~mm}$, showing that increasing the FA content did not have a significant effect on the workability. Finally, it was observed that samples with FA had less workability, regardless of the FA dosage, when compared with the optimum sample, where the highest difference recorded was $40.25 \mathrm{~mm}$ between NA10-100 and NA10-90.

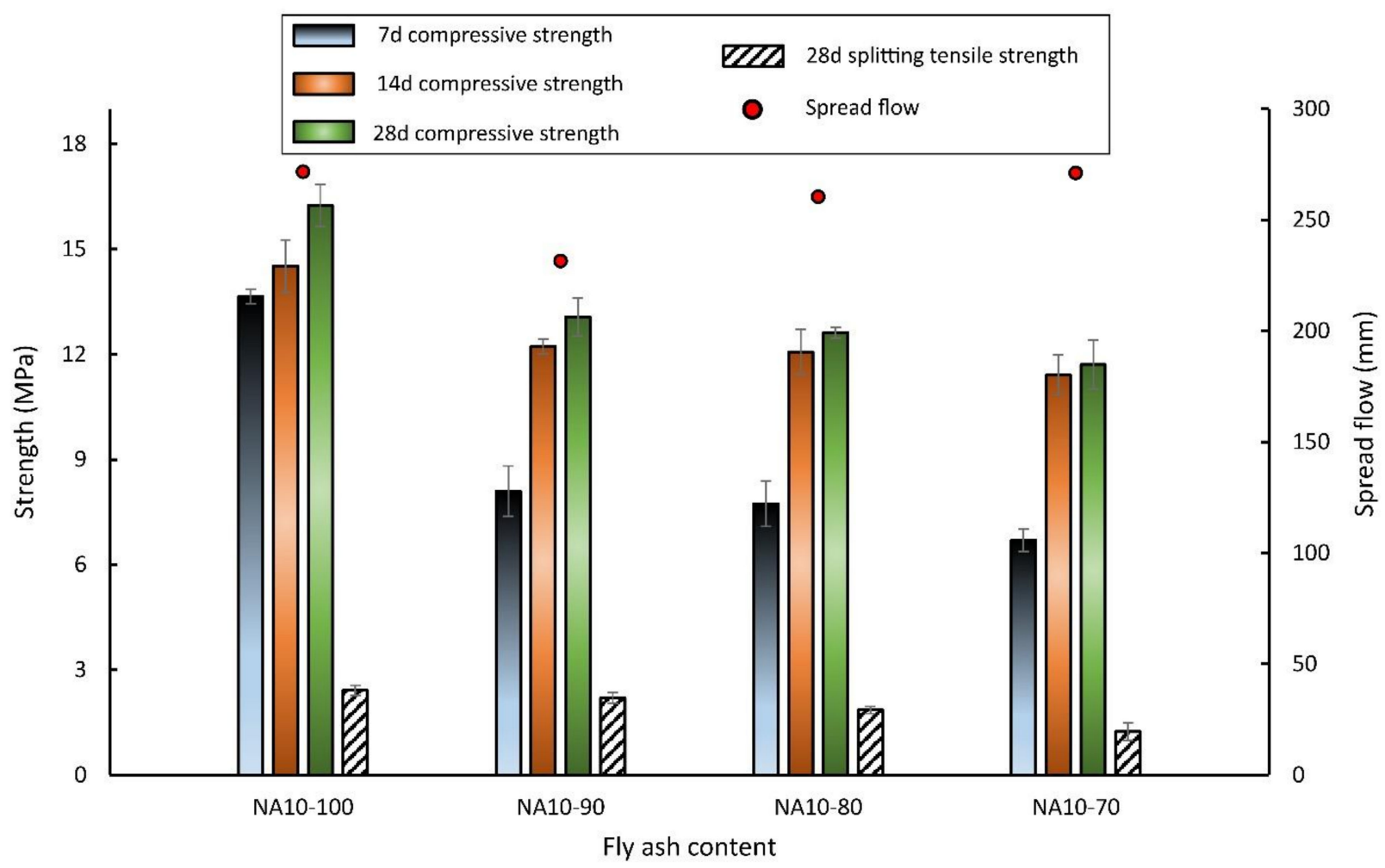

Figure 9. Flow spread and compressive and splitting tensile strengths of mortar when replacing the binder with fly ash $(0-30 \%)$ in the presence of the optimum concentration of nano- $\mathrm{Al}_{2} \mathrm{O}_{3}$ particles $(10 \%)$.

Incorporating different amounts of FA into the optimum sample influenced its mechanical properties. The results for the compressive strength and splitting tensile strength of the optimum sample with varying FA content are presented in Figure 9, which also show its strength development over 28 days. Generally, the compressive strength of the FA specimens was less than that of the optimum sample (NA10-100), regardless of the curing duration. For example, in the early stages, the compressive strength of the specimen containing $10 \%$ FA (NA10-90) was $40.6 \%$ less than that of the optimum specimen with $0 \%$ FA (NA10-100). The drop in compressive strength was further increased with increasing amounts of FA, wherein at a 30\% FA addition, the 7 day compressive strength was $50.9 \%$ less compared with that of NA10-100. It is also worth noting that the strength development between 14 and 28 days was insignificant. Although the negative effects of the FA content on the compressive strength were obvious, the presence of $10 \%$ NA helped with the strength development of the FA specimens. It was observed at 7 days the strength reduction between NA10-100 and the sample with 30\% FA was 50.9\%, whereas at 28 days, the strength reduction between the same samples was only $28 \%$. Meanwhile, the splitting tensile test results are shown in Figure 9, which reveal that although the splitting strength 
initially increased with the $10 \%$ NA addition compared with the reference, the inclusion of FA into the optimum mixture gradually decreased this value. With the addition of $10 \%$ FA, the splitting strength decreased by $9.1 \%$ when compared to NA10-100; however, this value is slightly similar to that of the reference, with a difference of only $0.08 \mathrm{MPa}$. With the addition of $30 \% \mathrm{FA}$, the reduction in the splitting tensile strength was further increased at $48.6 \%$ when compared to the optimum sample. Moreover, the lowest splitting tensile strength value of $1.24 \mathrm{MPa}$ was achieved with 30\% FA (NA10-70). It was also observed that the decrease in the splitting strength was higher at $32.9 \%$ between $20 \%$ and $30 \%$ FA when compared with the $15.7 \%$ strength reduction between $10 \%$ and $20 \%$ FA, showing that having a high amount of FA significantly decreased the strength.

\subsection{Water Absorption}

The capillary water uptake is an important indication of the durability of concrete. The reference, optimum, and FA specimens were all observed in a water absorption test for 6 days, as summarized in Table 2. Two phases of water absorption were observed in all samples. During the initial water uptake, the optimum sample containing $10 \%$ NA had higher water absorption than the reference sample. However, after achieving the secondary water uptake stage at $20 \mathrm{~h}$, the optimum sample had less water absorbed. This showed that the addition of $10 \%$ NA improved the water resistance of the sample. However, the addition of FA, regardless of the dosage, decreased the water permeability resistance of the specimens. Increasing the FA content gradually increased the water uptake during the secondary water absorption stage. It was noticed that both the initial and secondary absorption stages of the specimens with $20 \%$ and $30 \%$ FA had insignificant differences within 6 days of testing. Finally, the results revealed that it required approximately $20 \mathrm{~h}$ to reach the secondary absorption stage for the reference and optimum samples, whereas a longer time of approximately $40 \mathrm{~h}$ was required for the FA specimens to reach the plateau.

Table 2. Water absorption rate of the sample containing the optimum concentration of nano- $\mathrm{Al}_{2} \mathrm{O}_{3}$ particles $(10 \%)$ and different contents of fly ash (0-30\%).

\begin{tabular}{|c|c|c|c|c|c|c|}
\hline \multirow{2}{*}{ Absorption Phase } & \multirow{2}{*}{ Measured Time (h) } & \multicolumn{5}{|c|}{$A_{T}^{*}\left(\mathrm{~g} / 100 \mathrm{~cm}^{2}\right)$} \\
\hline & & Reference & NA10-100 & NA10-90 & NA10-80 & NA10-70 \\
\hline \multirow{8}{*}{ Initial absorption } & 0.00 & 0.00 & 0.00 & 0.00 & 0.00 & 0.00 \\
\hline & 0.25 & 22.92 & 20.37 & 19.86 & 21.14 & 20.12 \\
\hline & 0.50 & 30.05 & 30.56 & 28.01 & 28.27 & 28.27 \\
\hline & 1.00 & 39.73 & 43.04 & 41.51 & 39.73 & 38.96 \\
\hline & 2.00 & 55.77 & 63.66 & 56.28 & 54.88 & 52.71 \\
\hline & 4.00 & 72.57 & 87.09 & 82.00 & 79.45 & 75.38 \\
\hline & 6.00 & 83.27 & 105.93 & 103.39 & 99.06 & 93.97 \\
\hline & 24.00 & 153.81 & 147.19 & 154.06 & 150.24 & 148.62 \\
\hline \multirow{5}{*}{ Secondary absorption } & 48.00 & 159.15 & 149.73 & 167.56 & 170.36 & 169.09 \\
\hline & 72.00 & 160.43 & 150.24 & 169.60 & 172.40 & 172.65 \\
\hline & 96.00 & 160.68 & 150.50 & 170.10 & 173.42 & 172.91 \\
\hline & 120.00 & 160.43 & 150.50 & 170.36 & 173.16 & 173.16 \\
\hline & 144.00 & 161.19 & 151.01 & 170.36 & 173.16 & 172.91 \\
\hline
\end{tabular}

* $A_{T}$ : Water uptake.

\section{Discussion}

\subsection{Preliminary Study}

The screening study showed that the addition of NA and MA both had a positive effect on the mechanical properties of the cement-based composites. The compressive strength gradually increased between a 5\% and 15\% NA and MA addition, and the splitting tensile strength improved with a $10 \%$ NA addition. The specimens with NA consistently showed higher compressive and splitting strengths compared with specimens with MA at similar doses. This was due to NA being finer than MA and thus having a more effective filling 
effect, where it was able to fill the voids in between the cement and sand particles. Moreover, the ability of NA to gradually increase the strength of the mortar specimens was due to the high specific surface area of the nanoparticles, which caused an increase in nucleation sites for the formation of hydration products, making the structure denser and more compact [22]. In other words, the nanoparticles promoted high activity and accelerated cement hydration. The results followed the same trend of strength improvement with other studies [23-25], confirming that the presence of nanoparticles such as $\mathrm{SiO}_{2}, \mathrm{Fe}_{3} \mathrm{O}_{4}$ and $\mathrm{TiO}_{2}$ enhanced the mechanical properties of cementitious composites.

Furthermore, it was observed that increasing the NA content more than required would decrease the mechanical properties. This strength reduction was particularly seen in the splitting tensile strength results after $10 \%$ NA. Although the addition of small doses of NA initially improved the strength, adding too many nanoparticles generally caused problems in dispersion, wherein the nanoparticles started to agglomerate and prevent the growth of $\mathrm{Ca}(\mathrm{OH})_{2}$ instead of promoting them [26]. Moreover, a high amount of nanoparticle increased agglomeration, which caused weak zones to form and contributed to the decrease in strength [27]. According to previous studies [22,28], this was observed in NA doses higher than 2-3\%. However, the strength reduction in this study was not observed until more than $10 \%$ NA was added, which may be due to the characteristics observed during the material characterization. Although the individual particles of NA appear to be under $15 \mathrm{~nm}$ in Figure 1b, these were clustered and clumped together due to the moisture content. This made the particle dispersion effective, even at relatively high nanoparticle content amounts at 5\% and $10 \%$.

It is also worth noting that the strength reduction observed with another NA study [28] was related to the low and unacceptable workability of the specimens, which was not the case in this study. The results of the flow table tests in Figure 6a appeared to decrease the flowability with the increasing particle content; however, the change was relatively small. Moreover, it was observed that the workability of the specimens with NA was always less than the workability of the specimens with MA due to the higher surface area of NA. This was generally expected, as introducing a high-surface area material into the mixture increased the need for water, but the physical and physicochemical properties of such high-surface area powders affect the performance of fresh pastes differently [28]. Although the workability decreased slightly with NA and MA additions, the water content in the formula was sufficient for the amount of $\mathrm{Al}_{2} \mathrm{O}_{3}$ particles present, which resulted in acceptable flowability even at high particle doses (10-15\%). Finally, it was determined that the optimum mixture was with the presence of $10 \%$ NA, since it showed improvements in the compressive strength and the highest splitting tensile strength without its workability suffering.

\subsection{Strength Development of the Optimum Sample}

The strength development of the optimum sample NA10-100 was studied. As presented in Figure 8a,b, both the compressive strength and the splitting tensile strength increased over the 28 day curing period. The increase in strength of the optimum sample between 7 and 28 days was attributed to a gradually increasing pozzolanic reaction within the cement matrix as the curing time prolonged. It was generally expected that the strength developed over the curing time, regardless of the additive $[5,23,29]$. However, it was observed in this study that the strength development of the reference surpassed the optimum sample at 28 days. This means that although the presence of $10 \%$ NA had significant positive effects on the strength during the early stages, the rate at which it improved the strength decreased over time (after 7 days). It may be that $10 \%$ promoted early strength due to high activity, but after 7 days, there was limited space for the $\mathrm{Ca}(\mathrm{OH})_{2}$ crystals to grow, and the quantity of crystals was reduced [26]. This factor caused the NA10-100 specimen to have a lower strength than the reference at 28 days. The same strength development was observed in a previous study [23] that used nano- $\mathrm{Al}_{2} \mathrm{O}_{3}$, wherein the rate of strength development after 7 days decreased. 


\subsection{Effect of the Fly Ash Content on an Optimum Sample Containing 10\% NA}

The effect of the FA content was investigated for the optimum sample containing $10 \%$ NA. The strength development of the FA samples NA10-90, NA10-80 and NA10-70 between 7 and 28 days is shown in Figure 9. It was observed that the compressive strength of all the FA specimens increased over the curing duration, which was attributed to the growth of the hydration products over time [30]. However, it was also observed that the addition of FA caused a generally lower compressive strength in the mortar specimens, compared with the reference. Similarly, a gradually decreasing splitting tensile strength was observed with the increasing FA inclusion. Firstly, this was due to the components present in FA, namely $\mathrm{Al}$ and Si ions, which influenced immature pozzolanic activity and the prevention of the growth of hydration products [30]. According to Tanakorn et al., the amount of FA in the composite was also linked to the absence of $\mathrm{CaCO}_{3}$ in the cementitious matrix [29]. Moreover, the difference in size and morphology of the FA and cement contributed to the decrease of the mechanical properties, wherein the presence of FA created more voids in the matrix [30]. These factors contributed to the strength reduction of the FA specimens. This was observed in other studies [29-31], wherein the presence of FA typically had drawbacks and reduced the performance of specimens, regardless of which type of nanoparticle was present. However, the presence of nanoparticles could overcome the drawbacks caused by FA. In this study, it was observed that due to the presence of $10 \%$ NA, the strength development of the FA specimens improved over 28 days due to the nanoparticles affecting the hydration kinetics within the composite [32]. Nanoparticles have the ability to counteract the negative effects of fly ash on the mechanical properties of cement-based composites, where the presence of nanoparticles promotes hydration and reduces the toxic influences of components dissolved from FA [30]. Furthermore, FA has a slight effect on workability, wherein a 10\% FA addition initially decreases the flow spread but subsequently increases it with up to a 30\% FA addition. This is because the fineness of the fly ash can affect the water demand of the mortar, as observed with $45 \%$ FA in a previous study [33]. Since the FA content in this research was focused on doses under $30 \%$, the effect of high amounts of FA on the workability was not as pronounced.

Water absorption is an important indicator of the durability of concrete. The results of the water absorption tests on the reference, optimum sample and FA samples are presented in Table 2. Nanoparticles can fill the voids in the cement matrix, which increases the packing density, and enhanced packing leads to the enhanced resistance to water absorption [34]. This behavior was observed in this study, wherein at the secondary water absorption stage, the water uptake of the optimum sample was less than the water uptake of the reference. However, the increasing presence of FA introduced in the FA study decreased the water permeability resistance of the specimens. This can be seen in the water uptake graph, wherein all the FA samples (10-30\% addition) have a higher water uptake than the reference and optimum sample over 6 days. This was due to the difference in the morphology of cement and FA, as confirmed in characterization study. FA occurred in ball shapes, whereas cement occurred in bulky, amorphous structures. The difference in morphology affected the compaction of the mortar samples [30]. Due to difficulties in compaction with increasing amounts of FA, the amount of voids in the matrix increased, which in turn increased the water absorption and decreasing the strength of the specimens.

\section{Conclusions}

Nano- and micro- $\mathrm{Al}_{2} \mathrm{O}_{3}$ were introduced to mortar samples in different doses. The characteristics of cement mortar were evaluated through compressive and splitting tensile strength tests, flow table tests and capillary water absorption tests. The results show that the inclusion of micro- and nano-sized $\mathrm{Al}_{2} \mathrm{O}_{3}$ particles had varying effects on the physical and mechanical properties. In general, NA improved the strength of mortar specimens due to high pozzolanic activity. It was also found that NA improved the mechanical properties better than MA due to its higher surface area and void-filling characteristics. Compared with the control samples, the experimental results show that the addition of $5 \%$ 
NA and MA increased the compressive strength by $34 \%$ and $9.9 \%$, respectively. Further additions of NA and MA up to $15 \%$ led to an increase in the compressive strength by $42 \%$ and $22.7 \%$. However, the resulting splitting strengths for this level of particles $(15 \%)$ were lower than the control specimens and the lower dosages of NA and MA (5-10\%). Moreover, the addition of NA and MA decreased the flowability of fresh pastes, although the change was relatively small. An optimum dosage of $10 \%$ NA was determined from the preliminary study, and it was used for further study on the effects of FA on mortar specimens. Exceeding the amount of nanoparticles required started to decrease the strength, due to the excessive amount of additive inhibiting the growth of crystals. It was found in the FA study that increasing the amounts of FA in the optimum sample decreased the compressive and splitting strengths, as well as the durability through water resistance. For example, in the early stages, the compressive strength of the specimen containing $10 \%$ FA with $10 \%$ NA was $40.6 \%$ less than that of the optimum specimen without FA. In terms of the splitting tensile strength, with the addition of $10 \% \mathrm{FA}$, the splitting strength decreased by $9.1 \%$ compared with sample NA10-100. However, this value is slightly similar to that of the control specimen, with only a $0.08 \mathrm{MPa}$ difference. The negative effects of FA are mainly attributed to the insufficient compaction of rounded FA particles compared with amorphous cement powder. However, the presence of $10 \%$ NA improved the strength development of the specimens. This was explained as the ability of nanoparticles to counteract the effect of FA on the mechanical properties of mortar samples.

Author Contributions: Conceptualization, M.S. and A.B.; methodology, S.M. and M.S.; validation, S.M. and A.B.; formal analysis, S.M. and M.S.; investigation, S.M.; writing-original draft preparation, S.M. and M.S.; writing-review and editing, M.S. and A.B.; visualization, S.M. and M.S.; supervision, M.S.; funding acquisition, M.S. All authors have read and agreed to the published version of the manuscript.

Funding: This research was funded by the University of Waikato, New Zealand, grant number RTCF: $[107303,2020]$.

Institutional Review Board Statement: Not applicable.

Informed Consent Statement: Not applicable.

Data Availability Statement: Data sharing is not applicable to this article.

Conflicts of Interest: The authors declare no conflict of interest.

\section{References}

1. Sanchez, F.; Sobolev, K. Nanotechnology in concrete-A review. Constr. Build. Mater. 2010, 24, 2060-2071. [CrossRef]

2. Rashad, A.M. A synopsis about the effect of nano- $\mathrm{Al}_{2} \mathrm{O}_{3}$, nano- $\mathrm{Fe}_{2} \mathrm{O}_{3}$, nano- $\mathrm{Fe}_{3} \mathrm{O}_{4}$ and nano-clay on some properties of cementitious materials-A short guide for Civil Engineer. Mater. Des. 2013, 52, 143-157. [CrossRef]

3. Gaitero, J.J.; Campillo, I.; Mondal, P.; Shah, S.P. Small changes can make a great difference. Transp. Res. Rec. 2010, $2141,1-5$. [CrossRef]

4. Han, B.; Yu, X.; Ou, J. Self-Sensing Concrete in Smart Structures; Butterworth-Heinemann: Oxford, UK, 2014.

5. Sikora, P.; Horszczaruk, E.; Cendrowski, K.; Mijowska, E. The Influence of nano- $\mathrm{Fe}_{3} \mathrm{O}_{4}$ on the microstructure and mechanical properties of cementitious composites. Nanoscale Res. Lett. 2016, 11, 182. [CrossRef]

6. Qing, Y.; Zenan, Z.; Deyu, K.; Rongshen, C. Influence of nano-SiO 2 addition on properties of hardened cement paste as compared with silica fume. Constr. Build. Mater. 2007, 21, 539-545. [CrossRef]

7. Jo, B.W.; Kim, C.H.; Tae, G.H.; Park, J.B. Characteristics of cement mortar with nano-SiO 2 particles. Constr. Build. Mater. 2007, 21, 1351-1355. [CrossRef]

8. Khoshakhlagh, A.; Nazari, A.; Khalaj, G. Effects of $\mathrm{Fe}_{2} \mathrm{O}_{3}$ nanoparticles on water permeability and strength assessments of high strength self-compacting concrete. J. Mater. Sci. Technol. 2012, 28, 73-82. [CrossRef]

9. Vipulanandan, C.; Mohammed, A. Smart cement modified with iron oxide nanoparticles to enhance the piezoresistive behavior and compressive strength for oil well applications. Smart Mater. Struct. 2015, 24, 125020. [CrossRef]

10. Oltulu, M.; Şahin, R. Single and combined effects of nano- $\mathrm{SiO}_{2}$, nano- $\mathrm{Al}_{2} \mathrm{O}_{3}$ and nano- $\mathrm{Fe}_{2} \mathrm{O}_{3}$ powders on compressive strength and capillary permeability of cement mortar containing silica fume. Mater. Sci. Eng. A 2011, 528, 7012-7019. [CrossRef]

11. Seifan, M.; Sarmah, A.K.; Ebrahiminezhad, A.; Ghasemi, Y.; Samani, A.K.; Berenjian, A. Bio-reinforced self-healing concrete using magnetic iron oxide nanoparticles. Appl. Microbiol. Biotechnol. 2018, 102, 2167-2178. [CrossRef] [PubMed] 
12. Argiz, C.; Menéndez, E.; Moragues, A.; Sanjuán, M.A. Fly ash characteristics of Spanish coal-fired power plants. Afinidad 2015, 72, 269-277.

13. Cho, Y.K.; Jung, S.H.; Choi, Y.C. Effects of chemical composition of fly ash on compressive strength of fly ash cement mortar. Constr. Build. Mater. 2019, 204, 255-264. [CrossRef]

14. ASTM. Standard Test Methods for Sampling and Testing Fly Ash or Natural Pozzolans for Use in Portland-Cement Concrete; ASTMC311/C311M-16; ASTM International: West Conshohocken, PA, USA, 2016.

15. ASTM. Standard Test Method for Flow of Hydraulic Cement Mortar; ASTMC1437-16; ASTM International: West Conshohocken, PA, USA, 2015.

16. ASTM. Standard Test Method for Compressive Strength of Hydraulic Cement Mortars; ASTMC109-16; ASTM International: West Conshohocken, PA, USA, 2015.

17. ASTM. Standard Test Method for Splitting Tensile Strength of Cylindrical Concrete Specimens; ASTMC496/496M-16; ASTM International: West Conshohocken, PA, USA, 2017.

18. ASTM. Standard Test Method for Rate of Water Absorption of Masonry Mortars; ASTMC1403-15; ASTM International: West Conshohocken, PA, USA, 2015.

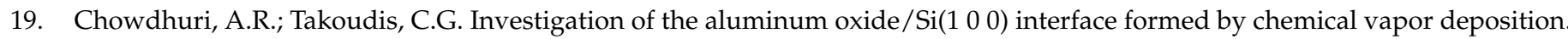
Thin Solid Films. 2004, 446, 155-159. [CrossRef]

20. Naayi, S.; Hassan, A.; Salim, E. FTIR and X-ray Diffraction Analysis of Al2O3 Nanostructured Thin Film Prepared at Low Temperature Using Spray Pyrolysis Method. J. Nanoelectron. Mater. 2018, 11, 1-6.

21. Kim, H.-J.; Nam, S.-M. High loading of nanostructured ceramics in polymer composite thick films by aerosol deposition. Nanoscale Res. Lett. 2012, 7, 92. [CrossRef] [PubMed]

22. Arefi, M.; Javeri, M.; Mollaahmadi, E. To study the effect of adding $\mathrm{Al}_{2} \mathrm{O}_{3}$ Nanoparticle on the mechanical properties and microstructure of cementmortar. Life Sci. J. 2011, 8, 613-617.

23. Mohseni, E.; Miyandehi, B.M.; Yang, J.; Yazdi, M.A. Single and combined effects of nano-SiO ${ }_{2}$, nano- $\mathrm{Al}_{2} \mathrm{O}_{3}$ and nano-TiO ${ }_{2}$ on the mechanical, rheological and durability properties of self-compacting mortar containing fly ash. Constr. Build. Mater. 2015, 84, 331-340. [CrossRef]

24. Li, L.G.; Zhu, J.; Huang, Z.H.; Kwan, A.K.H.; Li, L.J. Combined effects of micro-silica and nano-silica on durability of mortar. Constr. Build. Mater. 2017, 157, 337-347. [CrossRef]

25. Czarnccki, L.; Schorn, H. Monuments. Nanomonitoring of Polymer Cement Concrete Microstructure/Untersuchung des Mikrogefiiges von Polymer-Zement-Beton im Nanobereich. Restor. Build. Monum. 2007, 13, 141-152. [CrossRef]

26. Li, H.; Zhang, M.-H.; Ou, J.-P. Abrasion resistance of concrete containing nano-particles for pavement. Wear 2006, 260, 1262-1266. [CrossRef]

27. Li, H.; Xiao, H.-G.; Yuan, J.; Ou, J. Microstructure of Cement Mortar with Nano-Particles. Compos. Part B Eng. 2004, 35, 185-189. [CrossRef]

28. Nazari, A.; Riahi, S.; Riahi, S.; Shamekhi, S.; Khademno, A. Influence of Al2O3 nanoparticles on the compressive strength and workability of blended concrete. J. Am. Sci. 2010, 6, 6-9.

29. Tanakorn, P.; Chindaprasirt, P.; Sata, V.; Hanjitsuwan, S.; Hatanaka, S. The effect of adding nano-SiO 2 and nano- $\mathrm{Al}_{2} \mathrm{O}_{3}$ on properties of high calcium fly ash geopolymer cured at ambient temperature. Mater. Des. 2014, 55, 58-65.

30. Lin, D.F.; Lin, K.L.; Chang, W.C.; Luo, H.L.; Cai, M.Q. Improvements of nano-SiO 2 on sludge/fly ash mortar. Waste Manag. 2008, 28, 1081-1087. [CrossRef] [PubMed]

31. Adak, D.; Sarkar, M.; Mandal, S. Effect of nano-silica on strength and durability of fly ash based geopolymer mortar. Constr. Build. Mater. 2014, 70, 453-459. [CrossRef]

32. Amin, M.; Gamal, S.M.A.; Hashem, F. Effect of addition of nano-magnetite on the hydration characteristics of hardened Portland cement and high slag cement pastes. J. Therm. Anal. Calorim. 2012, 112. [CrossRef]

33. Vimonsatit, V.; Chindaprasirt, P.; Ruangsiriyakul, S.; Sata, V. Influence of fly ash fineness on water requirement and shrinkage of blended cement mortars. KKU Eng. J. 2015, 42. [CrossRef]

34. Zhang, B.; Tan, H.; Shen, W.; Xu, G.; Ma, B.; Ji, X. Nano-silica and silica fume modified cement mortar used as Surface Protection Material to enhance the impermeability. Cem. Concr. Compos. 2018, 92, 7-17. [CrossRef] 